\title{
TRANSMITINDO CONEXÕES: A CONSTRUÇÃO DO VÍNCULO PSICOTERÁPICO NO PSICODRAMA BIPESSOAL ON-LINE
}

\author{
Gabriela Pereira Vidal ${ }^{1, *}$ (D), Amanda Castro ${ }^{1,2}$ (B)
}

\section{RESUMO}

Este estudo teve o objetivo de compreender como se desenvolve o vínculo psicoterápico no psicodrama bipessoal on-line. Trata-se de uma pesquisa-ação, por meio de um estudo de caso de uma mulher de 20 anos, com a análise das cinco primeiras sessões de cerca de 50 minutos. Foi possível concluir que o vínculo no psicodrama on-line apresenta diferenças em relação ao presencial, porém denota-se que são muitas as contribuições psicodramáticas no desenvolvimento deste, tanto da teoria (visão de homem e de mundo) quanto também das técnicas psicodramáticas.

PALAVRAS-CHAVE: Vínculo; Psicodrama; On-line; Psicoterapia.

\section{TRANSMITTING CONNECTIONS: THE CONSTRUCTION OF THE PSYCHOTHERAPEUTIC BOND IN BIPERSONAL ONLINE PSYCHODRAMA}

\section{ABSTRACT}

This study aimed to understand how the psychotherapeutic bond develops in bipersonal online psychodrama. This is an action research, through a case study of a 20-year-old woman, with an analysis of the first five sessions of about 50 minutes. It was possible to conclude that the link in online psychodrama has differences in relation to the face-to-face, but it is noted that there are many psychodramatic contributions to its development, from the theory (man and world view) as well as psychodramatic techniques.

KEYWORDS: Bond; Psychodrama; Online; Psychotherapy.

\section{TRANSMITIR CONEXIONES: LA CONSTRUCCIÓN DEL VÍNCULO PSICOTERAPÉUTICO EN EL PSICODRAMA BIPERSONAL EN LÍNEA}

\section{RESUMEN}

Este estudio tuvo como objetivo comprender cómo se desarrolla el vínculo psicoterapéutico en el psicodrama bipersonal en línea. Se trata de una investigación acción, a través de un estudio de caso de una mujer de 20 años, con un análisis de las cinco primeras sesiones de unos 50 minutos. Se pudo concluir que el vínculo en el psicodrama online tiene diferencias en relación al presencial, pero se observa que son muchos los aportes psicodramáticos a su desarrollo, tanto desde la teoría (hombre y cosmovisión) como desde las técnicas psicodramáticas.

PALABRAS CLAVE: Vínculo; Psicodrama; Online; Psicoterapia.

1.Viver Mais Psicologia - Tubarão (SC), Brasil.

2.Universidade do Extremo Sul Catarinense - Criciúma (SC), Brasil.

*Autora correspondente: gabrielavidaal@gmail.com

Editora de Seção: Heloisa Fleury

Recebido: 08 Nov 2020 | Aceito: 06 Mar 2021 


\section{INTRODUÇÃO}

Com apenas um clique, qualquer pessoa pode conhecer vários países, diversas culturas e se relacionar com pessoas diferentes a quilômetros de distância. Surgiram muitas inovações e serviços que possibilitam o acesso de maneira mais cômoda, econômica e sem a necessidade de locomoção, como consultar portais do governo, realizar operações bancárias, fazer compras e consumir informações.

Dentre tais inovações, a psicoterapia é mais um dos serviços oportunizados por meio das tecnologias digitais, facilitando o acesso de pessoas que têm algum tipo de dificuldade de realizar psicoterapia de forma presencial. Esse serviço é regulamentado pelo Conselho Federal de Psicologia, através da Resolução n. ${ }^{\circ}$ 11/2018, que se preocupa com a qualidade do serviço prestado e com a manutenção dos aspectos éticos. Diante da regulamentação, cada psicoterapeuta faz suas adaptações teóricas e técnicas (Conselho Federal de Psicologia, 2018).

O psicodrama é uma das abordagens de trabalho em psicoterapia, que foca nas relações e vínculos humanos. A qualidade do vínculo, na perspectiva psicodramática, baseia-se nas possibilidades de estabelecimento de relações télicas (fundamentada em uma reciprocidade e empatia mútuas) entre psicoterapeuta e cliente. E como essa vinculação se dá no contexto on-line? É necessário investigar como ocorre a construção do vínculo e formas de facilitá-la neste ambiente, entendendo que essa construção é essencial para um bom processo psicoterápico no psicodrama.

O ser humano é assim relacional, existe na relação e nos vínculos que desenvolve na sociedade (Nery, 2014). De acordo com Aguiar (1990), os papéis desempenhados pelo ser humano possuem três categorias de vínculos: atuais, residuais e virtuais. Os atuais estão relacionados às relações mantidas na realidade, concretas; os residuais são aqueles da memória vincular, que em algum momento foram atuais, mas que no agora estão desativados, porém podem se manifestar por natureza transferencial, representando um si mesmo do passado; e os virtuais estão no âmbito da fantasia, nos quais o sujeito vincula com objetos e personagens imaginários, míticos ou distantes da realidade concreta (Ricotta, 2002).

Além disso, a afetividade é um dos fundamentos na aprendizagem de papéis, e esse aprendizado emocional norteia as vivências afetivas do sujeito, tornando-se a motivação da conduta humana e do estabelecimento de vínculos (Nery, 2014).

A criança, nos processos de vinculação com o mundo e o outro, aprende a distinguir sensações que variam do "prazer" à experiência de "amor", vivendo sentimentos como ciúmes, inveja, medo, insegurança e compaixão até as sensações de "desprazer" que acarretam a vivência do "ódio", experimentando sentimentos de mágoa, ressentimento, decepção, culpa, desespero, rejeição, tristeza e raiva. (Nery, 2014, p. 41).

Bustos, ao se referir ao psicodrama, escreveu que "trata-se de uma teoria que tem como ponto inicial o vínculo", afinal, toda a teoria é baseada nas relações, e em cada relação construímos uma forma de vincular (Bustos, 1999, p. 17). Até mesmo no vínculo psicoterapêutico, cada cliente e cada psicoterapeuta têm uma maneira específica de vincular, sendo uma das tarefas do psicoterapeuta estar atento à forma como cada cliente vincula e também sua própria forma de vincular (Nery, 2014). Além disso, o vínculo está relacionado com a tele entre as pessoas, pois pressupõe uma forma de reciprocidade (Ricotta, 2002). A tele pode ser compreendida, do ponto de vista meramente individual, como "uma percepção acurada da situação, condição para o ato espontâneo" (Aguiar, 1988, p. 68). Ainda, de acordo com Aguiar (1988, p. 68) "uma boa aproximação inicial seria considerá-la como o encontro de espontaneidades".

Nery ainda ressalta que compreender os aprendizados dos papéis e do aspecto emocional dos vínculos pode nos servir como forma de liberar os potenciais criativos nossos e dos nossos clientes. A autora ainda ressalta que "vínculo é isso: não permite fórmulas para seu êxito, mas um contínuo aprendizado coexistencial”(Nery, 2014,p. 173). Enquanto psicoterapeutas, precisamos de certo distanciamento e objetividade em alguns pontos, para analisar a melhor conduta e a necessidade de cada cliente, mas ao mesmo tempo vivemos também uma aproximação com cada um deles diante de nós. Essa aproximação, de acordo com Nery (2014, p.173), seria "promovida pela intersubjetividade e pela 'com-paixão' com cada cliente". 
Gulassa (2007) ainda descreve os três C’s necessários para a coconstrução de um bom vínculo terapêutico, repassados por seu supervisor Luiz Amadeu Bragante: contrato, continência e confiança. Um bom contrato terapêutico é fundamental na psicoterapia, seja grupal ou individual, e busca estabelecer as regras que vão reger o processo, visando a um bom desenvolvimento do mesmo. Essas regras em geral referem-se a horário, frequência, faltas, duração dos atendimentos e outros. A continência se refere ao acolhimento do cliente através da escuta qualificada, do cuidado com ele, proporcionando um local de livre expressão e sem julgamentos. Por fim, a confiança é estabelecida através dos dois anteriores, fazendo com que o sujeito se sinta à vontade no processo (Gulassa, 2007).

A maneira de vinculação desenvolvida pelos sujeitos interfere nas suas relações, inclusive na relação com o psicoterapeuta. Assim, é preciso entender como ocorre o vínculo na psicoterapia on-line, um cenário novo para os psicoterapeutas e, especificamente, para os psicodramatistas, tendo em vista ser esta abordagem psicoterápica objeto de discussão no presente artigo. Tal cenário implica novas formas de ver e de se relacionar com o corpo, através da câmera, de posições e posturas, do que o paciente escolhe compartilhar como plano de fundo, em que o contexto social pode se atualizar inadvertidamente no contexto dramático, por meio de barulhos ou interrupções da sessão, e que necessitam da criatividade para a manutenção do aquecimento ou mesmo para sua utilização em cena (Aroldo Jr., 2020).

Diante disso, a construção desta pesquisa começou em janeiro de 2020, quando a psicoterapia on-line ainda não era tão utilizada quanto no momento de sua aplicação, durante a pandemia da Covid-19. O interesse por esta investigação surgiu diante da ampliação dos atendimentos on-line sem nenhum contato presencial prévio. Ou seja, os novos clientes já iniciavam nessa modalidade, diferentemente do que as autoras vivenciavam até o início desta pesquisa, quando já realizavam atendimentos de psicoterapia on-line com clientes que iniciavam presencialmente e migravam depois para este formato. Assim, o objetivo desta análise foi compreender como se desenvolve o vínculo psicoterápico no psicodrama bipessoal on-line.

\section{MÉTODO}

Trata-se de pesquisa-ação, pois há envolvimento ativo do pesquisador com o sujeito de pesquisa e com os processos de planejamento, intervenção e avaliação das ações (Monteiro et al., 2006). Caracteriza-se também como estudo de caso, por apresentar um único objeto, visando amplo e detalhado conhecimento dele (Eisenhardt, 1989).

O caso relatado será do atendimento e vínculo com uma cliente que procurou uma das pesquisadoras para um processo psicoterápico on-line. Serão relatadas as cinco primeiras sessões de psicoterapia psicodramática bipessoal on-line, de 50 minutos cada, realizadas na plataforma Zoom. Os encontros foram gravados e posteriormente transcritos. A participante Marcela (nome fictício), 20 anos, cursa Psicologia e já havia feito psicoterapia de forma presencial, na época em virtude da separação dos pais, com outra psicoterapeuta. A queixa inicial foi de sensação de ansiedade, e a cliente não fazia uso de medicação.

Nesta pesquisa-ação com o psicodrama como objeto de investigação, foram utilizados os instrumentos do psicodrama bipessoal, que, em relação aos instrumentos originais, não faz uso do público, já que este não faz parte da psicoterapia bipessoal (Cukier, 1992; Vidal \& Castro, 2020). Os instrumentos utilizados nestas sessões foram: diretor - o psicoterapeuta que conduz o psicodrama, neste caso, a pesquisadora/psicoterapeuta; protagonista - a pessoa na qual está centrada a ação dramática; o ego-auxiliar - que no psicodrama bipessoal on-line poderá ser o próprio diretor/ pesquisador ou objetos para representação, como almofadinhas, canetas e outros; e o cenário - que no ambiente on-line será a união do local da câmera do pesquisador e do participante (Rodrigues, 2007; Vidal \& Castro, 2020).

A análise e a discussão teórica foram realizadas a partir dos preceitos epistemológicos e teóricos da socionomia de Jacob Levy Moreno e pós-morenianos. Além disso, a mesma não será voltada à descrição de cada sessão, mas sim dos manejos relacionados ao vínculo, objeto de estudo desta pesquisa. A pesquisa foi submetida ao Comitê de Ética e Pesquisa em Seres Humanos e aprovada sob o Parecer n. ${ }^{\circ}$ 4.057.859. A participante foi consultada acerca do interesse em participar do estudo e aceitou formalmente, através de um Termo de Consentimento Livre e Esclarecido. 


\section{MANEJOS RELACIONADOS AO VÍNCULO}

\section{Sessão 1}

Marcela inicia a sessão muito tímida, fala pouco, mas à medida que a diretora ${ }^{1}$ segue fazendo algumas perguntas, ela se abre a esse novo vínculo. A diretora continua com a primeira etapa de uma sessão de psicodrama, o aquecimento, momento no qual há uma preparação para a ação dramática (Cukier, 1992). Assim, a diretora prossegue direcionando as perguntas e auxiliando Marcela a ordenar seus pensamentos, pois ela fala de muitas questões que gostaria de trabalhar em psicoterapia.

Nesta sessão, a diretora procura conhecer o átomo social ${ }^{2}$ da cliente, utilizando o desenho em papel, registrado pela cliente com uma foto enviada para a diretora durante a sessão. Nesse desenho ela coloca suas principais relações sociais e a diretora segue pedindo que ela assuma o papel $^{3}$ de algumas das pessoas do átomo. Assim, na dramatização, a diretora conduz uma entrevista no papel com os personagens das relações representadas no átomo, buscando conhecer mais sobre a cliente a partir dos personagens por ela desempenhados e, ao mesmo tempo, aquecer-se em relação ao caso.

Ao fim desta sessão, o momento do compartilhamento tem início, com a diretora mostrando um pouco de seu consultório, seu cenário, algo que foi mencionado no início da sessão, mas que a diretora decide mostrar apenas no final, após o estabelecimento inicial do vínculo. Nesse momento da sessão, a cliente também está mais tranquila e solta, assim, segue mostrando também seu quarto, local onde realizará as sessões de psicoterapia.

Ainda no momento do compartilhamento, a diretora pede que Marcela afaste-se um pouco da câmera, de forma que consiga visualizar o corpo da cliente, e pede que ela faça uma imagem corporal que expresse como se sentiu no vínculo durante a sessão. Marcela coloca os braços abaixados, ombros soltos e cabeça levemente inclinada para o lado. A diretora pede que ela dê uma legenda para essa imagem e Marcela responde "relaxada, à vontade".

\section{Sessão 2}

Marcela inicia a sessão falando sobre algo que aconteceu no fim de semana, uma situação na qual se sentiu inferior a uma colega de faculdade. Aprofundando um pouco mais a questão e, ao mesmo tempo, aquecendo-se junto com a cliente para a temática, a diretora pergunta mais a respeito. Marcela relata que nesses momentos é como se houvesse duas dela: uma negativa e uma que a apoia.

A diretora opta pela divisão em duas personagens: uma que apoia e a negativa, propondo que ela assuma o papel do eu que apoia e Marcela, o do eu negativo. Assim é feito, com a troca dos papéis ocorrendo em alguns momentos. Marcela no papel do eu negativo começa a ceder e dizer que está tentando e que gostaria de ser menos negativa.

Ao saírem dos personagens, a diretora questiona quais dessas vozes se parecem com alguém na vida de Marcela e ela responde que nenhuma das duas:

A voz que dizia que ela era boa era todo mundo que sempre elogiou a forma que a Marcela fazia as coisas, só que eu acho que ela se colocou como outra Marcela e ai surgiu essa que fala: "talvez as coisas não sejam assim. E se você for ruim?". De tanto falarem que ela era boa...

A diretora pergunta quem são essas pessoas que falavam tão bem dela e pede que ela feche os olhos e passe a colocar retratos deles em uma tela em branco. Marcela coloca algumas imagens mentalmente e a diretora pede que escolha a pessoa que mais se associa com essa necessidade de aprovação, e Marcela fala de sua mãe. A diretora assume o papel de Marcela inicialmente e segue invertendo, buscando a compreensão da situação. Marcela se dá conta de que a mãe deposita nos outros a culpa pelos próprios erros desde que a cliente era uma criança, o que de alguma maneira exerce influência sobre ela, que

1.Diretor é um dos instrumentos do psicodrama e se trata daquele que dirige (conduz) a sessão de psicoterapia (Rojas-Bermúdez, 2016).

2.Derivado do conceito de Moreno, criador do psicodrama, que afirma que o átomo social é o núcleo das relações que um indivíduo possui, as pessoas com quem se relaciona e que se relacionam com ele. O jogo explorativo de mesmo nome consiste em uma representação dessas relações que propicie uma investigação do contexto sociométrico do protagonista (Cukier, 1992).

3.Forma de funcionamento que o indivíduo assume no momento específico em que reage a uma dada situação, na qual outras pessoas ou objetos estão envolvidos (Moreno, 1975, p. 27). 
busca o erro em si o tempo todo, a falha. A diretora aquece a cliente para uma conversa da mãe com a Marcela criança em psicodrama interno ${ }^{4}$. No papel de mãe, a cliente fala do quanto Marcela é boa e que, caso ela erre, não há problema.

Em seguida, a diretora, ainda conduzindo o psicodrama interno, pede que Marcela vá voltando ao papel de adulta, que vê essa cena de fora e questiona como ela se sente vendo a mãe orientar a si mesma quando criança. Marcela responde: “acolhida". Com essa ação, a diretora conduz a cliente ao seu papel no momento presente, visando a uma contemplação da cena pela adulta. No compartilhamento, Marcela fala que se sente fortalecida para encarar a situação da faculdade.

\section{Sessão 3}

Marcela relata, nesta sessão, o sentimento de solidão que tem em alguns momentos, que aparece quando não tem ninguém para conversar pelo celular. A diretora propõe uma inversão de papéis, colocando a cliente no papel do celular. Marcela, através das perguntas da diretora no papel de celular, conta que ela o usa para não ficar sozinha e sem fazer nada, postando nas redes sociais e conversando com amigos, "quando algum está disponível". Conversar com alguém, para Marcela, cumpre o papel de acalmar a solidão.

Além disso, Marcela relata, no papel do celular, que não compreende o que a deixa com essa sensação de solidão. Em seguida, a diretora decide por um psicodrama interno. Assim, pede que Marcela feche os olhos e visualize-se com a sensação de solidão, e então passa a fazer perguntas para aquecer a si mesma e a cliente. No psicodrama interno surge uma cena na qual ela se sentiu sozinha:

Uma vez, quando eu era bem, bem pequenininha, não me recordo nem quantos anos eu tinha, a gente morava numa casa que era em cima de um morro e minha vó morava embaixo, então dava de ver a casa da minha vó. E essas minhas duas tias se reuniram na casa da minha vó pra fazer um almoço e não convidaram a gente. E eu acho que desde essa época tenho essa sensação.

A protagonista chora ao relatar essa cena, abre os olhos em alguns momentos e depois volta a fechar. A diretora percebe que, nessa cena, o medo de ficar sozinha talvez se relacione ao medo da rejeição do outro. Conforme trabalham a cena, a diretora faz perguntas e duplos - técnica que consiste em expressar emoções não verbalizadas pelo cliente, com o objetivo de auxiliá-lo nessa expressão (Cukier, 1992) —, até que pergunta se Marcela quer ir até a casa da avó e ela responde que não, pois não foi convidada. A diretora responde: "eu não fui convidada, não quero estar lá, o que que eu quero fazer nessa cena?". Novamente a protagonista responde que não sabe. A diretora explica que nesse espaço ela pode fazer aquilo que desejar, ir ou não ir, falar com algum personagem ou fazer algo a mais na cena e Marcela responde: "eu acho que faria algo com a minha mãe e meus irmãos".

A diretora pergunta se Marcela acredita que eles estão sentindo a mesma solidão que ela, e a protagonista confirma que sua mãe sim, os irmãos talvez não. Assim, a diretora utiliza-se da identificação com a mãe e pergunta o que a imagem dela lhe transmite, e Marcela responde tristeza, o mesmo sentimento que trouxe no início da sessão. A diretora pergunta o que ela (criança) gostaria de fazer pela mãe e a criança responde que gostaria de abraçar, dar conforto. A diretora sugere que faça isso, pergunta como é o abraço e que cheiro a criança sente. A cliente responde: "é bom, tem cheiro de mãe [risada]".

Em seguida, ainda nesse abraço, a diretora propõe uma troca de papéis e questiona à protagonista, agora no papel de mãe, o que está acontecendo. Nesse papel, ela responde que a família (avó e tias de Marcela) os exclui (ela, o irmão e a mãe), e surge a inferioridade. A diretora propõe que a mãe converse com a criança sobre isso, e ainda no psicodrama interno a cliente, no papel de mãe, passa a explicar para a criança que elas não são inferiores. Depois, trocam-se os papéis e a diretora repete a fala da mãe, e Marcela, enquanto criança, confirma. Assim, encerra-se o psicodrama interno.

Ao final, a diretora pede que, com algumas canetas que há em cima de sua mesa, Marcela mostre quem são as pessoas com as quais pode contar, que a lembram de que não está sozinha. No compartilhamento Marcela fala sobre o quanto tem

4.Procedimento realizado quando a pessoa não tem um material específico para trabalho. É como uma viagem ou uma aventura pelo inconsciente por intermédio de imagens visuais espontâneas (Fonseca, 2010). 
se sentido à vontade nas sessões e que esperava que não fosse assim, pois teve uma experiência anterior de psicoterapia presencial na qual não se sentiu vinculada à psicoterapeuta. Assim, finaliza-se a sessão.

\section{Sessão 4}

A sessão inicia com os cumprimentos iniciais e, logo em seguida, Marcela começa a relatar algo que aconteceu durante a semana. Ela conta que o irmão precisou de ajuda com alguma coisa e a mãe lhe pediu para auxiliar, porém ele começou a incomodá-la por não fazer do jeito que ele queria, e isso a deixou muito estressada. Assim, ela percebeu o quanto os irmãos sempre foram "cobrados" para fazer as coisas, enquanto ela sempre foi mais independente. Marcela também comenta que se flagrou pensando na relação disso com as coisas que já haviam sido trabalhadas nas sessões anteriores.

A diretora pede que ela relaxe na cadeira, respire fundo, feche os olhos e comece a imaginar o cenário onde essa cena pode acontecer. A protagonista relata o cenário e o desenrolar da cena: está na sala de casa e o irmão começa a mandar mensagem reclamando porque ela não havia pago um boleto que ele pediu, pois Marcela achou que poderia ser um boleto falso, e pediu à mãe que confirmasse com ele. Porém, na cena, quando o irmão ficou bravo e discutiu, ela não respondeu, não explodiu como sempre fazia. No papel do irmão, a diretora questiona essa ação, até que a protagonista responde que não explodiu para manter-se em segurança, para não ser julgada. A diretora retorna Marcela para o momento atual, pede que ela abra os olhos e diz: "quando foi antes, na sua história, que você conseguiu responder sem ter essa autocobrança de que seria errado ou feio?".

A protagonista relata um dia em que, durante um almoço, a mãe e ela experimentaram alguns coquetéis e, por beber demais, começou a reclamar porque irmão não auxiliava nas tarefas domésticas. A diretora aquece Marcela novamente, pedindo que feche os olhos e descreva o cenário e o início dessa cena. Segue a cena na qual Marcela relata sua insatisfação com o irmão, além de outras falas sobre como ninguém a entende e que ela só quer ser compreendida. A diretora pede que abra os olhos e faz um duplo espelho ${ }^{5}$ lhe mostrando a forma como falou com a mãe e o irmão, além de outras falas, de outras sessões, de Marcela cobrando algo dos outros. A cliente começa a chorar e constata que exige o tempo todo coisas dos outros. Ela relata não saber como agir diferentemente.

A diretora propõe que possam "chamar" alguém que sirva de referência para ela no "como se", e ela fala de uma amiga. No papel dessa amiga, passa um modelo de como agir, e depois, com o auxílio da diretora, fazem um role-playing na cena anterior. O role-playing, ou jogo de papéis, permite ao indivíduo atuar dramaticamente em diversos papéis, desenvolvendo assim um novo papel espontâneo e criativo, encontrando gradativamente, a partir de um papel predefinido, um grau de liberdade (Flores, 2019).

A cena termina com os três, Marcela, a mãe e o irmão, limpando a cozinha juntos. A diretora coloca Marcela no papel dos outros na cena e todos concordam que fica melhor assim e que as brigas podem diminuir. No momento do compartilhamento, Marcela ressalta que é muito difícil exigir algo da mãe. Nesse caso, pedir ajuda. Por isso, talvez as brigas surjam.

\section{Sessão 5}

Nesta sessão, Marcela já inicia falando sobre as duas semanas que passaram, já que o intervalo entre as sessões foi maior. No meio do diálogo, a paciente inicia o relato sobre como vem se sentindo com a psicoterapia, e a diretora conduz com ela essa reflexão, aproveitando para refletir com a cliente também sobre o vínculo das duas até o momento.

Assim, pede que a cliente represente como se sentiu em cada sessão com um objeto (do contexto social ou dramático). Posteriormente, solicita outros objetos que representem como estava o vínculo naquela sessão. Ela inicia representando a si mesma na primeira sessão com um espelho, pois diz que quando se colocou no papel da amiga, constatou coisas que não percebia. Para a representação do vínculo, a cliente escolhe um carregador de celular, explicando que a diretora é a tomada e ela seria o fio, e que nessa primeira sessão sentiu uma conexão entre ambas e percebeu o espaço como seguro.

5.São as técnicas duplo e espelho sintetizadas por Fonseca (2010) na psicoterapia da relação quando se está na frente do paciente dublando-o, utilizando ao mesmo tempo características de ambas as técnicas. 
Em relação à segunda sessão, na qual Marcela se comparava a uma amiga, ela escolhe uma régua para representar a si mesma, pois aprendeu a se medir com a sua própria régua nessa sessão. Já na representação do vínculo, escolhe um cadeado com uma chave e explica que foi conseguindo se destrancar mais.

Para a terceira sessão, na qual Marcela falou sobre o sentimento de rejeição, ela escolhe para representá-la uma boneca, pois relata perceber naquele momento que sua infância e as coisas que havia vivido naquele período ainda fazem parte do seu cotidiano e de suas ações atuais. Quanto ao vínculo, a protagonista representa com uma casa, um abrigo, um lar seguro, pois, de acordo com ela, sentiu-se acolhida para se abrir. Ela ainda afirma que em nenhum momento sentiu uma insistência da diretora, apenas uma coordenação, para fazer aquilo que estivesse nos seus limites.

Representando a si na quarta sessão, Marcela escolhe uma luva de boxe, pois disse que estava explodindo, e isso refletia em tudo na sua vida. Ela continua explicando que essa sessão foi uma luta, a que mais a abalou. Marcela afirma também perceber que no início da psicoterapia trouxe assuntos nos quais ela estava em posição de vítima, quase como se estivesse mostrando ser uma boa pessoa, e que depois dessa sessão percebeu que conseguiu mostrar sua raiva e comportamentos agressivos, pois o vínculo já havia se consolidado. Ela representa o vínculo desta sessão com um boxeador, pois explica que estava muito resistente e com raiva.

Para a última sessão, ela escolhe peças de montar para representá-la, pois, de acordo com a cliente, conforme vai colocando uma peça em cima da outra, percebe que precisa da base para que a de cima consiga estar ali, mesmo que às vezes seja difícil encaixar as peças, como na vida.

Ao finalizar a sessão, a cliente descreve que tem se sentido confortável e protegida nas sessões on-line, por estar na sua própria casa, em virtude de a diretora ser de outra cidade e ela saber que não a encontrará facilmente no local onde mora, e por não perder tanto tempo para chegar ao consultório, o que ocorreria caso as sessões fossem presenciais. Ela ainda relata: "sinto que talvez, se fosse presencialmente, não teria ocorrido dessa forma, porque talvez eu não tivesse coragem de encarar, sabe?".

\section{DISCUSSÃO}

O vínculo psicoterápico se constitui mesmo antes de o cliente chegar ao psicoterapeuta. Assim, as informações on-line que Marcela obteve quando recebeu a indicação acerca da diretora e a conversa inicial de ambas, via aplicativo de conversa, já fazem parte do vínculo.

$\mathrm{Na}$ primeira sessão, quando a diretora pede para Marcela apresentar seu cenário, há dois motivos envolvidos nessa apresentação: no psicodrama on-line o cenário, enquanto instrumento, pode vir a ser a junção do espaço onde estão diretor e do protagonista. Assim, o conhecimento do espaço físico do protagonista é importante para que o diretor conheça os objetos e o espaço disponíveis neste, que podem vir a fazer parte das sessões em algum momento; um segundo motivo, este relacionado ao vínculo, é que este ato de apresentação dos espaços de cada um configura-se como parte do processo de vinculação, pois esses espaços visualizados no psicodrama on-line são normalmente muito pessoais, como o quarto, o trabalho, o escritório ou outros espaços, normalmente com objetos pessoais (Vidal \& Castro, 2020). Ainda sobre essa apresentação, quando a diretora mostra seu consultório e pede para conhecer o espaço de Marcela, ela faz isso porque a junção de ambos caracterizam uma justaposição dos contextos social e grupal no psicodrama on-line, e através destes é que se inicia o processo vincular que fomentará o desenvolvimento do contexto dramático posteriormente (Vidal \& Cardoso, 2020; Menegazzo et al., 2019).

Nesta primeira sessão, quando a diretora solicita o uso de uma imagem corporal que representa como Marcela se sentiu, a imagem simbólica visa concretizar uma realidade interior da protagonista, as emoções que fazem parte do acontecimento ou da situação vivenciada, nesse caso, a sessão (Khouri \& Machado 2008). Muitas pessoas apresentam dificuldade na verbalização de sentimentos ou sensações. Assim, a diretora, ao perceber a timidez da protagonista nesse primeiro momento, sem ainda poder medir até onde esta ocorre em virtude de suas características pessoais ou da estranheza de um primeiro contato, utiliza a imagem para uma melhor compreensão acerca das percepções de Marcela e também da construção do vínculo entre ambas.

$\mathrm{Na}$ segunda sessão, a diretora utiliza-se muito do ato de pedir que a cliente feche os olhos buscando a inserção no imaginário para assumir ou trocar um papel. Esse ato funciona como uma demarcação na tomada dos papéis de maneira a favorecer o aquecimento do cliente (Vidal \& Cardoso, 2020). 
Ao fim dessa sessão, a diretora pede que Marcela represente como está se sentindo com a diretora utilizando uma palavra. A fala de Marcela corrobora com sua abertura à construção deste vínculo de maneira saudável. O vínculo psicoterapêutico é de extrema importância, visto que, através dele, o protagonista pode interiorizar aspectos vinculares, expandindo-os para outras relações, e assim, seu potencial criativo (Nery, 2014). O vínculo é baseado em uma relação dialógica e de empatia, proporcionando tanto a experiência relacional quanto a revivência psicodramática, para o reconhecimento de aspectos profundos e a liberação das cargas emocionais ligadas a eles (Ferreira-Santos, 2013).

$\mathrm{Na}$ terceira sessão, a diretora desempenha, muitas vezes, a voz e o papel de criança ou da própria cliente no psicodrama interno, o mesmo ocorrendo em outras sessões. $\mathrm{O}$ ato de assumir esse papel, na falta de um ego-auxiliar, é comum no psicodrama bipessoal (Naffah Neto, 1997) e também no ambiente on-line (Vidal \& Castro, 2020).

Ao fim desta sessão, quando a diretora pede que represente as pessoas que denotam que a cliente não está sozinha, ela o faz para que Marcela lembre-se disso no "como se", para que também se lembre na vida. Aqui se denota a importância da concretização, técnica que, de acordo com Santos (2020, p.113), "abrange a representação de objetos inanimados, partes do corpo e entidades abstratas (vínculo, emoção, conflito)”, como uma forma de visualizar situações ou sentimentos, auxiliando para que a cliente constate aqueles que estão ao seu lado e se fortaleça sabendo que pode contar com essas pessoas (Bustos, 2005; Cukier, 1992). Esse trabalho de reorganização dos vínculos atuais auxilia também no fortalecimento do vínculo entre diretora e cliente.

$\mathrm{Na}$ quarta sessão ocorreu uma percepção importante da diretora acerca do vínculo: Marcela, pela primeira vez no processo psicoterápico, mostrou-se agressiva, forte e em posição contrária à de vítima em uma cena. De acordo com Contro (2020), é importante perceber a construção do vínculo de maneira processual, unindo a cumplicidade e a confiança em cada momento, unindo conhecimento e sensibilidade. Esta percepção processual pode ser correlacionada ao conceito de aquecimento como uma etapa que se refere à preparação do personagem protagônico e também do diretor para a ação. Porém, aqui o aquecimento parece relacionado ao vínculo, ou seja, a relação terapêutica pode aquecer o protagonista para a ação dramática (Perazzo, 2019; Vidal \& Castro, 2020). Além disso, de acordo com Perazzo (2019), para a fluidez de uma dramatização, um primeiro ponto é a proximidade interior entre diretor e protagonista. À medida que se constitui a relação entre cliente e diretor, este vínculo passa também por um processo de aquecimento, no qual inicialmente a cliente mostrava seu lado "vítima” e, após esse aquecimento ao longo das sessões, está aquecida no vínculo a ponto de mostrar seu lado "agressivo", sem medo de retaliação ou julgamento. Com base nisso, o aquecimento aqui vai além de uma etapa da sessão, é parte do vínculo - escreve-se "parte" e não "etapa", pois sua manutenção é necessária a todo momento. Prova disso pode ser a periodicidade das sessões de psicoterapia, pois, com base nas experiências das autoras deste artigo, percebe-se que a ocorrência de intervalos maiores entre as sessões faz com que o diretor precise de mais tempo ou de iniciadores diferentes para o aquecimento.

Além disso, em relação ao vínculo, quando a cliente apresentou seu lado agressivo, a diretora lhe mostrou este através de espelhos e duplos, sem em momento algum julgá-la do ponto de vista da moralidade. Justamente por isso a mudança é tema recorrente na clínica psicodramática, e também no vínculo, com o objetivo de auxiliar o indivíduo a não negar este processo de transformação, mas sim buscar ressignificação do eu, desconstruindo aquilo que não the cabe mais e reconstruindo atos espontâneos em sua relação com o mundo (Gonçalves \& Peres, 2012).

Em relação à quinta e última sessão desta pesquisa, a diretora opta por um processamento unicamente verbal, uma linguagem pouco utilizada até então, em virtude da timidez da protagonista. Como Marcela estava muito reflexiva sobre as sessões anteriores, e de acordo com Contro (2020, p. 74), "toda expressão, verbal ou não, da parte do cliente que entra na sala e começa uma sessão merece que estejamos atentos", a diretora pede que escolha objetos que representem como se sentiu na sessão e como percebeu o vínculo. Esse uso dos objetos visa favorecer o aquecimento da cliente e, ao mesmo tempo, também o reconhecimento dela e de seu envolvimento (vínculo) com a psicoterapia. Assim, facilita-se, com esse simbolismo e com o aquecimento, que ela consiga expressar-se verbalmente (Schmidt, 2006). Nesse caso, Marcela utilizou objetos do contexto social, como canetas e outros, porém que representavam outros objetos no contexto dramático. Assim, os objetos passam a atuar como iniciadores de uma ação, neste caso, uma ação verbal (Vidal \& Castro, 2020).

À medida que a cliente trazia ao contexto dramático os objetos, a diretora processava verbalmente com ela o que eles representavam. Nery (2014) explica que a fala é um dos elementos da ação, no qual podemos perceber o discurso, os papéis latentes, a psicodinâmica e tantas outras possibilidades e necessidades de intervenções. 
De acordo com Ulkovski, Silva e Ribeiro (2017, p. 64), "no atendimento psicoterápico online a relação empática pode ocorrer com uma ressalva: é necessária mais atenção ao que se fala e escreve, do que ao que se visualiza, uma vez que essa visualização nem sempre é clara e precisa". A perspectiva das autoras se refere à limitação da imagem apenas àquilo que aparece na câmera ou dificuldades de visualização em virtude da qualidade da imagem ou conexão, evidenciando a importância da fala na psicoterapia on-line. Dessa forma, a comunicação verbal pode e talvez deva ser mais explorada na psicoterapia on-line e também no psicodrama on-line, pois "os vínculos estão na ação da fala, na fala da ação, na palavraação ou na ação-palavra (um todo indissociável)” (Nery, 2014, p. 218).

Ao refletir sobre a primeira sessão, a cliente comenta sobre a inversão de papéis realizada na descrição do átomo social em pauta. Sobre a importância do uso da inversão para a ampliação do vínculo, Nery (2014) destaca que a inversão proporciona profunda transmissão e também conexão das subjetividades do sujeito com as do outro. Assim, neste caso, quando a diretora utiliza da inversão de papéis, faz surgir a possibilidade de que a protagonista se reconheça nos vínculos e traga os próprios conteúdos, ampliando também o vínculo diretor-protagonista, por dois motivos: não é a diretora quem "aponta" as questões à protagonista, mas sim ela que percebe no papel; e assim podem vir à tona os conteúdos transferenciais.

Por fim, cabe a discussão sobre a tela. O psicodrama on-line trouxe a perspectiva da sociedade e do sujeito contemporâneo, ou seja, algumas gerações ou pessoas percebem como natural esse contato mediado por uma tela, tão natural quanto o presencial. Já para outras, este contato e as percepções sobre ele ocorrem de maneira oposta. Contro (2020) remete à generalização acerca dos sujeitos, à criação de rótulos de acordo com um mapeamento de condutas, e reforça que é preciso pensar e dar relevância ao tempo histórico de cada sujeito. Ou seja, uma geração que se desenvolver com um contato próximo à tecnologia contemporânea provavelmente sentirá maior conforto e facilidade com ela, percebendo inclusive a tela como uma interface segura, como afirmou a cliente desta pesquisa em alguns momentos, a exemplo de quando ela relata se sentir mais à vontade na psicoterapia on-line e diz que, se fosse presencialmente, acredita que não teria coragem. Nos atendimentos psicoterápicos on-line, pode-se pensar na tela como intermediária da relação, o que talvez possa ser relacionado à redução de estados de alarme, auxiliando no aquecimento necessário para o aqui e agora, e também atuando como uma espécie de proteção, comum nas relações virtuais.

\section{CONSIDERAÇÕES FINAIS}

Uma abordagem direcionada às relações humanas precisa acompanhar os locais nos quais essas relações acontecem. Há algumas mudanças no vínculo do psicodrama bipessoal on-line em relação ao presencial, dentre elas, a proximidade e a intimidade com o cliente, já que, ao iniciar uma videochamada, os clientes normalmente estão em locais pessoais de suas casas e estes "dizem muito sobre cada um" (Cardoso Jr., 2021, p. 69).

Em relação à fala da cliente relacionada à distância física, o fato de não residir na mesma cidade da diretora $\mathrm{e}$ psicoterapeuta lhe deu a segurança de saber que, caso não quisesse continuar o processo, não a encontraria pelas ruas de sua cidade tão facilmente. Uma diferença em relação à psicoterapia presencial está na restrição de ação corporal entre diretor e protagonista, o que gera a necessidade da busca de outras maneiras de comunicar e propiciar o acolhimento. Por exemplo, com essas alterações na comunicação, altera-se também a construção do vínculo. Acerca da construção deste, como discutido na análise, acredita-se ser possível uma associação do conceito de aquecimento do psicodrama para o vínculo na psicoterapia psicodramática, pois este também é construído gradativamente e exige uma manutenção.

Como contribuições da teoria psicodramática para a construção e manutenção do vínculo, pode-se destacar: a apresentação do local de atendimento da protagonista e da diretora, visando conhecer o espaço físico, como aquecimento para o início do processo vinculatório ("estou no meu quarto, aqui atrás tem essa estante com meus livros e aqui à direita está a janela"); o uso dos objetos, imagens corporais e outras representações que possibilitam uma melhor compreensão acerca da cliente; a compreensão do vínculo como construído em um ritmo confortável para a diretora e a cliente, respeitando os limites de cada um; a técnica de inversão de papéis para auxiliar a cliente na percepção de si mesma e dos outros nas cenas, auxiliando no vínculo com a diretora e em outros vínculos; o desenvolvimento de papéis ou demais condições importantes para a cliente com vistas à percepção de suas relações. 
Por fim, a protagonista, em seus compartilhamentos sobre o vínculo psicoterapêutico, ressaltou a evolução à medida que as sessões aconteciam, e que percebe que o ambiente on-line auxiliou nesse quesito. Apontou duas hipóteses para essa evolução: sua proximidade anterior com meios tecnológicos e a segurança que sentiu em não se encontrar com a diretora em locais de sua cidade (algo que aconteceu com a antiga psicoterapeuta).

Diante disso, cabe citar Rodrigues et al. (2020, p. 151) quando se referem ao ambiente on-line: "vencendo preconceitos, descobrem-se novas possibilidades", já que, em meio à pandemia, o ambiente on-line, já apreciado por poucos, tornou-se espaço de interesse de muitos. Enquanto autoras, acreditamos que o vínculo no psicodrama on-line apresenta diferenças em relação ao presencial; enquanto psicodramatistas, acreditamos que o uso da espontaneidade e da criatividade pode nos levar a possibilidades grandiosas nesse ambiente; e enquanto pesquisadoras, ressaltamos a necessidade de mais pesquisas, mais relatos de experiências e mais compartilhamentos na comunidade psicodramática acerca do ambiente on-line.

\section{CONTRIBUIÇÃO DAS AUTORAS}

Conceitualização: Vidal GP, Castro A; Investigação: Vidal GP; Escrita - Rascunho Original: Vidal GP; Revisão: Castro A; Supervisão: Castro A.

\section{DISPONIBILIDADE DE DADOS DE PESQUISA}

Não se aplica.

\section{FINANCIAMENTO}

Não se aplica.

\section{AGRADECIMENTOS}

Agradecemos a escola Viver Mais Psicologia, em especial a Viviane Almeida e Luciana Moskorz Kersbaumer pela leitura cuidadosa e sugestões no desenvolvimento desta pesquisa.

\section{REFERÊNCIAS}

Aguiar, M. (1988). Teatro da anarquia: Um resgate do psicodrama. Papirus.

Aguiar, M. (1990). O teatro terapêutico: Escritos psicodramáticos. Papirus.

Bustos, D. M. (1999). Novas cenas para o psicodrama. Ágora.

Bustos, D. M. (2005). O psicodrama: Aplicações da técnica psicodramática (3a ed.).

Cardoso Jr., A. de L. (2021). Stage, scene and body in online psychodrama. Revista Brasileira de Psicodrama, 29(1), 6570. https://doi.org/10.15329/2318-0498.21746

Contro, L. (2020). Nós e nossos personagens: Histórias terapêuticas. Ágora.

Cukier, R. (1992). Psicodrama Bipessoal: Sua técnica, seu terapeuta e seu paciente. Ágora.

Eisenhardt, K. M. (1989). Building theories from case study research. Academy of Management Review, 14(4), 532-550. https://doi.org/10.5465/amr.1989.4308385

Ferreira-Santos, E. (2013). Psicoterapia breve: Abordagem sistematizada de situaçôes de crise. Ágora.

Flores, D. (2019). Role playing, personal fulfillment and self-concept: Overcoming social vulnerability and developing spontaneity. Vivências, 15(29), 177-186. https://doi.org/10.31512/vivencias.v15i29.79 
Fonseca, J. S. (2010). Psicoterapia da relaçâo: Elementos de psicodrama contemporâneo. Ágora.

Gonçalves, C. O., \& Peres, V. L. A. (2012). O psicodrama na universidade: contribuições morenianas à psicoterapia em uma clínica-escola. Revista Brasileira de Psicodrama, 20(1), 71-92. http://pepsic.bvsalud.org/scielo.php?script=sci_ arttext\&pid=S0104-53932012000100007\&lng=pt\&tlng=pt

Gulassa, D. (2007). Vínculo e confiança em atendimento psicoterapêutico psicodramático grupal com presidiários. Psicologia ciência e profissão, 27(2), 332-341. https://doi.org/10.1590/S1414-98932007000200013

Khouri, G. S., \& Machado, M. L. (2008). Imagem psicodramática e a técnica da construção de imagens. In H.J.Fleury, G. S. Khouri, \& E. Hug, Psicodrama e Neurociência: Contribuiçôes para mudança terapêutica. Ágora.

Menegazzo, C. M. et al. (2019). Dicionário de psicodrama e sociodrama. Ágora.

Moreno, J. L. (1975). Psicodrama. Cultrix.

Monteiro, A. M. et al. (2006). Pesquisa qualitativa e psicodrama. Ágora.

Naffah Neto, A. (1997). Psicodrama: Descolonizando o imaginário. Plexus Editora.

Nery, M. P. (2014). Vinculo e afetividade: Caminho das relaçôes humanas (3a ed.). Ágora.

Perazzo, S. (2019). Ainda e sempre psicodrama (2a ed). Ágora.

Resolução n. ${ }^{\circ} 11$ do Conselho Federal de Psicologia, de 11 de maio de 2018 (2018, 14 maio). Regulamenta a prestação de serviços psicológicos realizados por meios de tecnologias da informação e da comunicação e revoga a Resolução CFP n. $11 / 2012$.

Ricotta, L. (2002). O Vinculo Amoroso: A trajetória da vida afetiva. Ágora.

Rodrigues, R. (2007). Quadros de referência para intervenções grupais: psico-sociodramáticas. DPSedes, 1-16. http:// www.sedes.org.br/Departamentos/Psicodrama/Quadros_referencia_Intervencoes_Grupais.pdf

Rodrigues, R. et al. (2020). Telepresencial Reprise Theater in COVID-19 times. Revista Brasileira de Psicodrama, 28(2), 142-153. https://doi.org/10.15329/2318-0498.20836

Rojas-Bermúdez, J. G. (2016). Introdução ao psicodrama. Ágora.

Santos, A. G. dos (2020). Autoapresentação, apresentação do átomo social, solilóquio, concretização e confronto. In R. F. Monteiro (Org.), Técnicas fundamentais do psicodrama [recurso eletrônico]. Summus.

Schmidt, M. L. G. (2006). A utilização do objeto intermediário no psicodrama organizacional: Modelos e resultados. Psicologia para América Latina, (8). http://pepsic.bvsalud.org/scielo.php?script=sci_arttext\&pid=S1870-350X2006000 400012\&lng=pt\&tlng=pt

Ulkovski, E. P. et al. (2017). Atendimento psicológico on-line: Perspectivas e desafios atuais da psicoterapia. Revista de Iniciação Científica da Universidade Vale do Rio Verde, 7(1), 59-68.

Vidal, G. P., \& Cardoso, A. S. (2020). On-line role play: Relationship psychotherapy and internal psychodrama in contemporary psychodrama. Revista Brasileira de Psicodrama, 28(2), 131-141. https://doi.org/10.15329/23180498.20293

Vidal, G. P., \& Castro, A. (2020). O Psicodrama Clínico On-line: Uma Conexão Possível. Revista Brasileira de Psicodrama, 28(1), 54-64. https://doi.org/10.15329/2318-0498.20196 